\title{
Urdimento
}

Revista de Estudos em Artes Cênicas

E-ISSN: 2358.6958

\section{Contribuições para uma história do teatro nas prisões do Brasil}

Viviane Becker Narvaes

\section{Para citar este artigo:}

NARVAES, Viviane Becker. Contribuições para uma história do teatro nas prisões do Brasil. Urdimento, Florianópolis, v. 3, n. 39, nov./dez. 2020.

DOI: http:/dx.doi.org/10.5965/14145731033920200101

Este artigo passou pelo Plagiarism Detection Software | iThenticate 


\title{
Contribuições para uma história do teatro nas prisões do Brasil
}

\author{
Viviane Becker Narvaes ${ }^{1}$
}

\begin{abstract}
Resumo
Este artigo, fruto de tese de doutorado recém defendida, apresentou aspectos históricos do teatro nas prisões do Brasil; propôs uma linha do tempo que incluiu antecedentes históricos desta modalidade de teatro e elencou experiências de teatro nas prisões brasileiras de 1937 a 2019. Na perspectiva da necessária sistematização dos estudos sobre o tema, certamente não se atingiu a totalidade das experiências de teatro em nossas prisões, mas a pesquisa realizada complementou o panorama histórico do teatro nas prisões elaborado por Concilio (2008) em sua dissertação de mestrado. Os debates do campo, bem como aspectos da relação arte e prisão no contexto nacional, numa ótica historicizada, foram abrangidos.
\end{abstract}

Palavras-chave: Teatro e Prisão. Teatro e Encarceramento. História do teatro.

\section{Contributions to a history of theater in prisons in Brazil}

\begin{abstract}
Aspects of theater in prisons in Brazil, lays out a timeline that includes historical antecedents of this theater modality, and lists theater experiences in Brazilian prisons from 1937 to 2019. In view of the necessary systematization of studies on the theme, this article certainly does not record all theater experiences in our prisons, but this research complements the historical panorama of theater in prisons elaborated by Concilio (2008) in his master's dissertation. The article covers debates in the field as well as aspects of the relationship between art and prison in the national context in a historicized perspective.
\end{abstract}

Keyword: Theater and Prison. Theater and Incarceration. History of theater.

\footnotetext{
${ }^{1}$ Profa. Dra. Adjunta IV da Universidade Federal do Estado do Rio de Janeiro - Unirio - e Chefe do Departamento de Ensino de Teatro. Graduação em Artes Cênicas pela Universidade Federal do Estado do Rio de Janeiro. Mestrado em Artes Cênicas pela Universidade Federal do Estado do Rio de Janeiro e Doutorado em Artes Cênicas pela Universidade de São Paulo (2020). vivianenarvaes@gmail.com
} 
Contribuciones a una historia del teatro en las cárceles de Brasil

\section{Resumen}

Este artículo, resultado de una tesis doctoral recientemente defendida, presentó aspectos históricos del teatro en las cárceles en Brasil; propuso una línea de tiempo que incluía antecedentes históricos de esta modalidad teatral y enumeraba las experiencias teatrales en las cárceles brasileñas de 1937 a 2019. Ante la necesaria sistematización de los estudios sobre el tema, ciertamente no todas las experiencias teatrales en nuestras cárceles, pero la investigación realizada complementó la Panorama histórico del teatro carcelario elaborado por Concilio (2008) en su tesis de maestría. Se abordaron los debates en el área, así como aspectos de la relación entre arte y prisión en el contexto nacional, en una perspectiva historizada.

Palabras clave: Teatro y prisión. Teatro y encarcelamiento. Historia del teatro. 
O presente artigo é um esforço de pesquisa e estudo sobre o teatro nas prisões do Brasil e visa contribuir para a inscrição desse campo na historiografia de nosso teatro. Para tanto, proponho a organização de uma linha do tempo que inclui antecedentes históricos desta modalidade de teatro e elenca experiências nas prisões brasileiras de 1937 a 2019. A abordagem teórico-metodológica adotada o compreendeu como um teatro das classes populares e, portanto, as dimensões de raça e classe fazem parte das análises.

Estabelecer um marco histórico basal para o encontro do teatro, ou das artes, com o cárcere não é uma tarefa fácil, pois de fato seria necessário pensar em uma situação prisional antecedente que impossibilitasse, em tempo integral, qualquer ímpeto expressivo do indivíduo encarcerado. Michael Balfour (2004, p. 2) remonta a um registro de 1870, desenhos feitos por indígenas presos em um forte estadunidense, e também aos registros de teatro e outras formas artísticas durante a Segunda Guerra Mundial². Balfour se refere, ainda, à probabilidade de que a conjunção arte/prisão certamente não tenha sido registrada, pois as condições de produção da arte na prisão concorrem para sua invisibilidade e, portanto, esse lapso indica a possibilidade de uma longínqua história dessa relação. Trata-se de uma questão em dois planos: num primeiro, mais pragmático, estabelece um recuo histórico e cronológico que se pode esgarçar mais, demarcando a existência de experiências ainda mais distantes no tempo, em que artesanato e arte possuíam fronteiras mais tênues, por exemplo. Num segundo plano aponta "o não registrado", que pode ganhar contornos variados do ponto de vista historiográfico, quais sejam, o esquecimento, o desaparecimento, o apagamento ou a invisibilidade.

Ao refletir sobre a história do teatro nas prisões do Brasil, conjuguei esses dois planos igualmente. Ao pensar sobre os pelourinhos brasileiros e o cárcere de nossas senzalas, estabeleci um recuo histórico e me deparei com processos de apagamento que aparecem de forma desigual e combinada conforme o típico

\footnotetext{
${ }^{2}$ Michael Balfour (2004, p. 2) faz referências a teatro em campos de concentração, nos guetos e nos gulags. Sobre teatro nos campos de concentração, também é importante destacar a tese de doutorado Teatro de Sami Feder: espaço poético de resistência nos tempos do holocausto (1933-1950), de Leslie Evelyn Ruth Marko (2016).
} 
desenvolvimento da sociedade brasileira. As experiências de arte originárias da população escravizada são amplamente verificáveis pela história de nossas manifestações populares como o jongo, o tambor de crioula, a capoeira e inúmeras outras. Todavia, ainda há, no campo da história do teatro, lacunas sobre atores, dramaturgia e demais aspectos de encenações com o protagonismo dessa população.

Evidente que em termos históricos, conceituais e institucionais, a Prisão e a Senzala possuem muitas diferenças, inclusive por suas funções na sociedade, mas também apresentam certas semelhanças, por isso vale a pena retomar um aspecto da história do teatro brasileiro que se refere à representação de Tamerlão na Pérsia em Cuiabá no Mato Grosso, em 1790.

Esta noite saiu a público a comédia Tamerlão na Pérsia, representada pelos crioulos. Quem ouvir falar neste nome dirá que foi função de negros inculcando neste dito a ideia geral que justamente se tem que estes nunca fazem coisa perfeita e antes dão muito que rir e criticar. Porém não é assim a respeito de certo número de crioulos que aqui há; bastava ver-se uma grande figura que eles têm; esta é um preto que há pouco se libertou, chamado Victoriano [...]. (Moura apud Prado, 2012, p. 45).

Embora o excerto acima enfoque o recém-liberto Victoriano, no conjunto de documentos investigados por Moura há referência à participação de escravos também. Não se trata aqui de situar essa representação como um teatro do cárcere, pois os estudos existentes a fazem figurar como um teatro amador inserido no contexto de um festejo popular, como se pode verificar no seguinte texto:

Um relato detalhado sobre a encenação de tragédias, comédias entremezes, farsas e bailes entre os dias 6 de agosto a 11 de setembro de 1790 foi publicado na revista do Instituto Histórico e Geográfico no final da década de 1880. (Budasz, 2008, p. 128).

Budasz afirma ainda que muitos eram os atores mulatos no Brasil do século XVII e faz referência a um poema de Gregório de Matos Guerra sobre um festejo de Nossa Senhora do Amparo que registrou essa realidade (Budasz, 2008, p.129). 
Esses registros de um teatro que tem participação de escravos, ex-escravos e de "pardos”, a quem se refere o poeta Gregório de Matos Guerra, auxiliam a constatar que nas senzalas já existiam experiências teatrais, principalmente se somarmos àqueles registros o conhecimento que temos hoje sobre a tradição dos Griot originária de alguns povos africanos.

No que se refere ao plano dos problemas historiográficos relacionados ao esquecimento, se poucos são os estudos sobre a arte e o teatro das classes subalternizadas, que dirá o desse estrato social de escravos, extremamente subalternizado, cujas histórias efetivamente poucos querem lembrar. A relação estabelecida acima, entre a prisão e a senzala, também ajuda a compreender que a pessoa encarcerada tem origem nas classes populares, em especial na realidade brasileira.

Desse modo, demonstrei as dificuldades de estabelecer um ponto de partida para uma cronologia das relações entre artes e encarceramento, bem como, mais especificamente no caso brasileiro, entre teatro e encarceramento. Não é à toa que em minha visada busquei um marco inicial que relacionasse o cárcere e a escravidão no Brasil, haja vista que a prisão repõe de certo modo a senzala no nosso tempo.

No Brasil contemporâneo, muitos são os trabalhos desenvolvidos nas prisões e, no que se refere à história das relações entre teatro e encarceramento, possivelmente a publicação mais importante é Teatro e Prisão: dilemas da liberdade artística, de Vicente Concilio (2006), originária de sua dissertação de mestrado. O autor realiza uma reflexão panorâmica da história de processos teatrais em presídios circunscritos ao Estado de São Paulo e levanta para tanto um conjunto de autores que se dedicaram a esse tema.

Ao olhar para o panorama histórico proposto por Concilio, incluo, além de antecedentes, o Teatro do Sentenciado - T.S $S^{3}$ um grupo significativo formado na São Paulo dos anos 1940 como mais um marco histórico na linha temporal. Ademais, com base na pesquisa bibliográfica realizada, somei algumas outras

${ }^{3}$ A sigla T.S, se referindo a Teatro do Sentenciado foi elaborada por mim com a finalidade de facilitar a escrita e leitura do texto evitando muitas repetições. 
experiências importantes, que organizo a seguir:

LINHA DO TEMPO

\section{TEATRO E PRISÃO NO BRASIL}

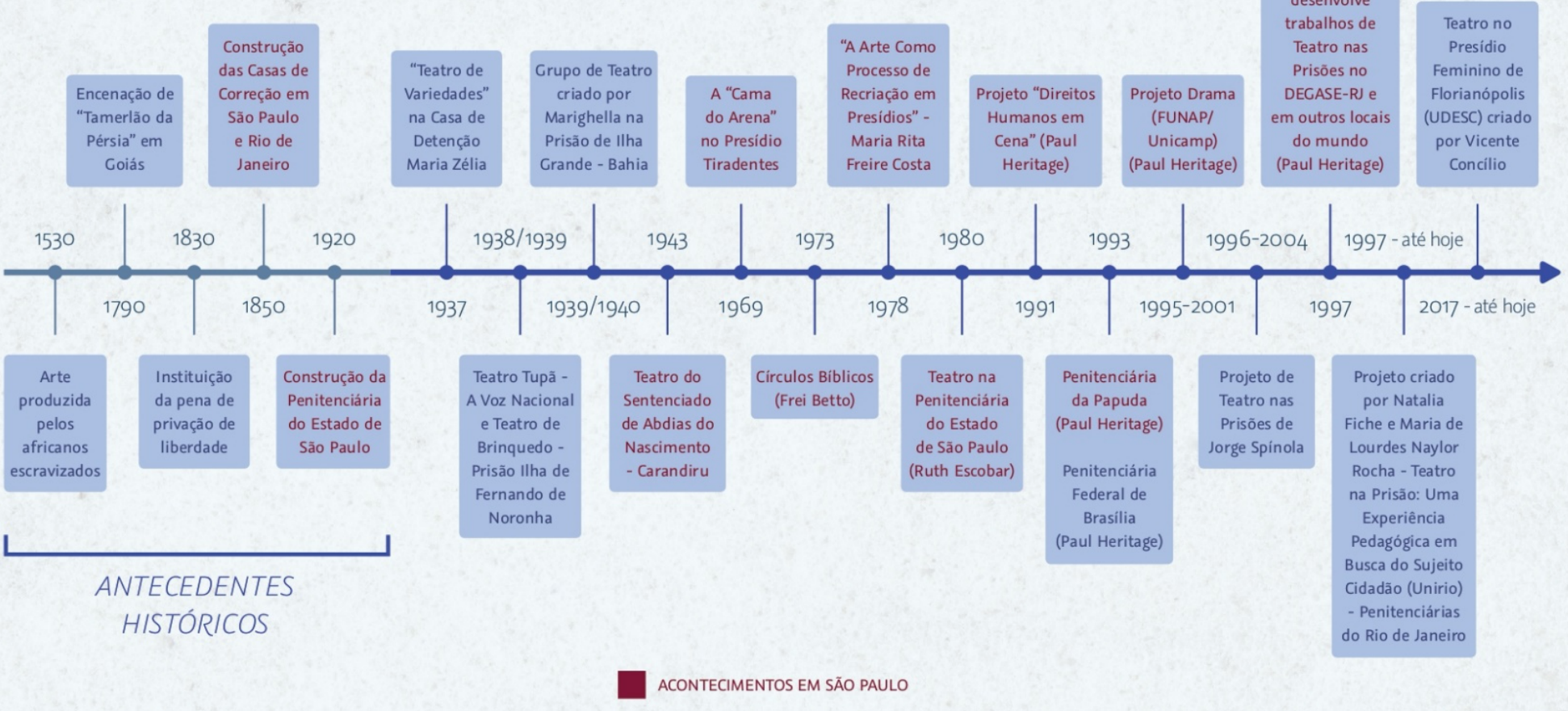

Fonte: Viviane Becker Narvaes. Design: Alice Cruz

\section{Demarcando antecedentes históricos}

De 1530 até 1920 considerei elementos que constituíram um conjunto de antecedentes históricos. Evidente que nesse largo tempo podem e devem ter existido outras práticas artísticas e/ou teatrais que ainda não foram iluminadas 
pelas pesquisas existentes e quiçá essa sistematização possa ser superada ou complementada por outros estudos. As expressões artísticas dos povos originais do Brasil não estão apontadas especificamente nas suas relações com o cárcere por merecerem um enfoque que escapa ao fôlego da pesquisa realizada.

No Brasil a maior parte da bibliografia sobre o tráfico dos primeiros escravos negros aponta seu início para a década de 30 dos anos 1500. Estabeleci, portanto, como antecedente esse marco, ponderando que a população africana que começou a desembarcar no Brasil trouxe consigo um manancial cultural que foi se adaptando e se transformando nas senzalas.

Em 1790, conforme destacado anteriormente, a presença de escravos na encenação de Tamerlão da Pérsia em Goiás também é um marco prévio significativo.

Em 1830 aponto a instauração de um Código Penal próprio no Brasil que incluiu a pena de privação de liberdade.

Em 1850 se constroem as primeiras Casas de Correção no Rio de Janeiro e em São Paulo e em 1920 a Penitenciária do Estado de São Paulo (Carandiru) foi construída. Nesse período portanto se encerram as demarcações dos antecedentes históricos.

Conjugar escravidão e sistema penal nesses antecedentes se relaciona fortemente com um dos mais importantes exemplos de teatro na prisão que constam na linha temporal, qual seja, o Teatro do Sentenciado.

Nos primeiros anos da década de 40, na fundação do grupo, o sistema prisional estava revivendo uma crise que o acompanhou quase que desde seu estabelecimento no Brasil. Havia poucas unidades prisionais, o número de presos aumentava e o quadro era, portanto, de mais presos do que vagas em unidades prisionais. As condições e perfil da população carcerária da década de 1940 no Carandiru não diferem muito das de hoje em que temos 64\% da população carcerária composta por pessoas negras. 
Contribuições para uma história do teatro nas prisões: Vila Maria Zélia, Marighella, Abdias Nascimento e Arena

Durante o Estado Novo, em 1937, a Vila Maria Zélia, na Zona Leste de São Paulo, foi convertida em prisão política:

Lá ficaram em torno de setecentos detentos, homens como Quirino Pucca, Abdon Prado Lima, Fúlvio Abramo e Paulo Emílio Sales Gomes. O local ganharia fama como "Universidade Maria Zélia", pela quantidade de intelectuais encarcerados. Aparentemente, os organizadores da "universidade" foram o corretor de café Roberto Silva (seu "diretor"), Quirino Pucca, Ermelindo Maffei, Clóvis Gusmão, Reginaldo de Carvalho e Caio Prado Júnior, que teria até mesmo "assessorado" Djalma Maranhão em palestras sobre a Sociologia do Cangaço! (Pericás, 2016, p. 104).

Mas a "Universidade" era, sobretudo, uma prisão destinada a sufocar a militância do PCB e, portanto, as condições eram terríveis, incluíam interrogatórios, torturas e todas as privações do cárcere. No entanto, na biografia de Caio Prado Junior (Pericás, 2016) aparece uma breve referência ao teatro: "No dia 19 de janeiro, os detentos assistiram a um "teatro de variedades", com cantos e recitações, uma reunião de atores que passaria a ocorrer todos os domingos, dali em diante" (Pericás, 2016, p. 105). Essa, portanto, é a referência mais antiga que encontrei sobre teatro na prisão, convertendo-se no ponto inicial da linha do tempo. É sabido que Paulo Emílio Sales Gomes, enquanto esteve preso na Vila Maria Zélia, escreveu a peça "Destinos" em 19364", no entanto não encontrei informações para verificar quando foi encenada no local.

Ainda no contexto das prisões políticas, Mário Magalhães ao biografar Marighella afirma que entre 1938 e 1939 na ilha de Fernando de Noronha, convertida em prisão, existiram dois grupos de teatro, o Teatro Tupã - a voz nacional ligado aos integralistas e o Teatro de Brinquedo ligado à Aliança Nacional Libertadora. Marighella fez parte desse último e, ao ser transferido para o presídio de Itha Grande na Bahia entre 1939 e 1940, buscou reproduzir a experiência

\footnotetext{
4 Mantive na linha do tempo o ano de 1937, devido ao registro na obra de Pericás (2016).
} 
organizativa vivenciada em Fernando de Noronha e lá criou também outro grupo de teatro.

Em 1943, Abdias Nascimento e seus companheiros de prisão criaram, no interior da unidade prisional em que estavam encarcerados, a Penitenciária do Estado de São Paulo (o Carandiru), o grupo Teatro do Sentenciado. Realizaram seis encenações, todas em 1943, algumas cenas curtas, ou "cenas brasileiras", conforme as identifica Nascimento, e números musicais. As apresentações tiveram suas datas de estreia conforme o que segue, mas eram repetidas ocasionalmente para familiares e funcionários. Os espetáculos encenados foram: O Preguiçoso, no dia 2 de agosto, Defensor Perpétuo do Brasil, provavelmente em 7 de setembro, 0 dia de Colombo e Revista Penitenciária, no dia 12 de outubro, Patrocínio e a República, no dia 15 de novembro, e Zé Bacôco, no dia 4 de dezembro. As cenas brasileiras foram Apertura de Simplício e Zé Porqueiro, Pimpinelli e suas extravagâncias, Mais uma do Pimpinelli e números de ilusionismo e prestidigitação. Os números musicais eram apresentados pelos grupos Jazz Cristal $^{6}$ e Conjunto Regional Anjos do Ritmo. A invisibilização da pessoa presa e o fato de que a sociedade não quer lembrar nem enxergar seus presos e suas histórias são fatores que contribuíram para que esse grupo tenha ficado muito tempo sem ser estudado.

A escolha da palavra "Sentenciado" para compor o nome do grupo está relacionada ao funcionamento do sistema prisional daquele período. Do início do século até a década de quarenta existia um número enorme de pessoas encarceradas nas casas de correção. Essas prisões tinham por característica o fato de serem feitas discricionariamente pelos chefes de polícia sem processo jurídico ou formalizado em outras instâncias que não a da polícia. Diferente era o caso da Penitenciária do Estado de São Paulo, nela só estavam presentes os condenados

\footnotetext{
${ }^{5}$ A designação "cenas brasileiras" parece ser de uso corrente na época, pois, nas edições de 17 e 18 de novembro de 1943 do jornal Folha de São Paulo, respectivamente nas páginas 2 e 7, consta a coluna Rádio, assinada por "Quincas Borba", que se refere a uma transmissão radiofônica de "cenas brasileiras". O rádio certamente era ouvido na penitenciária e pode ter influenciado essa nomenclatura.

${ }^{6}$ A grafia original é Jaz Cristal, um abrasileiramento da palavra jazz, que embora possa remeter o leitor de hoje à ideia de jazer, não tinha esse objetivo.
} 
devidamente processados e sentenciados.

O personagem principal dessa história é Abdias Nascimento, pois é a ele que se deve o registro dessa experiência, tanto nos documentos pessoais de seu acervo quanto na produção escrita a respeito. No entanto, o T.S possuía outros protagonistas dentre os 54 integrantes que o compuseram ao longo de sua existência. Era formado exclusivamente por pessoas presas e condenadas, como o próprio nome indica. Nas fontes de pesquisa encontradas e consultadas, a identificação dos integrantes aparece de forma diversa, alguns nomes completos, alguns nomes parciais ou apenas as iniciais. Na maior parte dos documentos constam apenas os números correspondentes a cada homem encarcerado, mas foi possível identificar com precisão os seguintes integrantes: Abdias Nascimento, Péricles Stuart Leão, Armando Waldomiro de Andrade, Messias Nogueira dos Santos, Benedito Braga, Francisco Faria Junior, Lino Catarino, José Pistone e Domingos Farina. Outros poderiam ser adicionados a esta lista, mas a identificação apenas numérica me impediu de os retratar neste texto.

As peças do Teatro do Sentenciado mostram uma variedade formal. 0 Preguiçoso foi uma comédia ligeira, O Defensor Perpétuo do Brasil, uma comédia histórica, O dia de Colombo pode ser enquadrado como Teatro de Variedades, $A$ Revista Penitenciária, Teatro de Revista, Patrocínio e a República, comédia histórica, Zé Bacôco, uma comédia musical. As formas distintas que o grupo utilizou demonstram um desenvolvimento técnico de suas habilidades, bem como a busca por aperfeiçoamento.

No Teatro do Sentenciado seus integrantes aprenderam a dominar as diversas etapas do processo de produção de seus espetáculos, tais como feitura de cenário, figurino, construção do palco entre outras. Experimentaram também diferentes formas teatrais e desenvolveram produção dramatúrgica. Tudo isso reforça a ideia de autonomia dos setores populares ao criar suas formas próprias de expressão, que no caso em tela se deu num momento de modernização das instituições brasileiras projetado pelo Estado Novo. As contradições desse processo apareceram na produção do grupo. 
Anos depois, em 1969, em meio à ditadura civil-militar brasileira, os artistas do Teatro de Arena passam por sequestros e prisões, portanto esse momento precisa ser assinalado num histórico do teatro nas prisões no Brasil. Ao relatar o período de sua prisão, Augusto Boal revela três elementos que são por demais marcantes. O primeiro se refere à "cama cativa" do Arena, que não ficava vazia na cela desde 1969. O segundo diz respeito à dinâmica de formação e estudos entre os presos políticos que dedicavam o horário da tarde a aulas, nas quais "cada um ensinava o que sabia, como nos CPCs"” (Boal, 2014, p. 323), e a ele cabia ensinar teatro. O terceiro elemento remonta à criação da peça Torquemada e do romance Milagre no Brasil, cuja escritura no papel se concretizou bem depois, porém foram literalmente "desenhados"8 no cárcere.

Eu aproveitava as visitas maternas para fazer sair desenhos que rabiscava a fim de fazer lembrar episódios que gostaria de contar quando livre. Minha mãe, revistada dizia que os desenhos eram para meu filho. Assim, desenhei um romance, Milagre no Brasil, e Torquemada, peça. (Boal, 2014, p. 324).

No período da ditadura houve morte, sequestro e prisão de militantes independente de classe, o que em aparência reduziu a seletividade penal, pois era preciso calar quem se contrapunha ao regime. Essa dimensão da seletividade aparece no tratamento diferenciado destinado aos presos comuns e políticos, bem como entre os próprios presos políticos. Se por um lado a separação tinha em vista o controle dos presos, pois o encontro e confinamento de diferentes classes sociais era potencialmente perigoso, por outro lado reforça-se o argumento de que mesmo no estado de exceção a prisão é parte da estrutura social vigente e reflete a organização social. Na sociedade capitalista em especial, uma parcela da população não tem futuro. E a vivência da prisão e da tortura de Boal impactou profundamente sua trajetória:

Metaforicamente, o Teatro do Oprimido nasceu na prisão. Gosto de dizer:

\footnotetext{
${ }^{7}$ Centros Populares de Cultura.

${ }^{8}$ Não foi possível localizar no banco de dados do Instituto Augusto Boal os referidos desenhos. Para consulta de mais informações vale acessar: http://acervoaugustoboal.com.br/. Acesso em: fev. 2020.
} 
nele o cidadão, no presente, estuda o passado e inventa o futuro. O palco, a arena, como a cela ou pátio da cadeia, podem ser esse lugar de estudo; o teatro, instrumento adequado, linguagem dessa fala, busca de si. (Boal, 2014, p. 330).

Essa passagem tem um forte apelo poético e poderia ser interpretada com um grau de idealização do espaço da prisão, pois num ambiente de controle e desmantelamento do sujeito, como é possível estudar? Como é possível projetar um futuro? Contudo, a intervenção concreta do Teatro do Oprimido nas prisões, que se deu muitos anos depois em mais de trinta presídios, contrapõe à ideia de agência individual processos coletivos de trabalho teatral, visando à ação no presente para projetar e transformar o futuro, dando materialidade àquele pensamento de Boal.

\section{Teatro na prisão dos anos 1960 a 1990}

O trabalho de Vicente Concilio é a referência no campo do teatro nas prisões para os estudos históricos desse período.

De 1969 a 1973, Concilio (2008, p. 39-41) destaca a experiência de Frei Betto, que enquanto esteve preso organizou os Círculos Bíblicos, os quais, como se infere do título, iniciaram-se com as reuniões de leituras da Bíblia e só posteriormente dialogaram com o teatro, gerando dois espetáculos teatrais que inclusive foram assistidos por uma plateia externa ao presídio. Da experiência de Frei Betto, que diferente de Boal cumpriu pena por dois anos entre os presos políticos (1969 a 1971) e por mais dois anos entre os presos comuns (1971 a 1973), mais elementos podem ser identificados no que se refere à questão de classe nos presídios e aos processos de protagonismo das classes populares.

Em 1978 Maria Rita Freire Costa, Elias Andreatto, Eros Volúzia, Conceição D'Incao, Iolanda Hussak e Ademir Martins realizaram um total de cinco espetáculos com uma dramaturgia fortemente marcada pelas vivências de mulheres encarceradas. A qualidade dos processos teatrais permitiu a visibilidade do trabalho e o grupo obteve autorização para se apresentar fora da prisão. No 
entanto, essa experiência resultou na fuga de três detentas no dia da apresentação (Concilio, 2008, p. 41-49). A experiência foi registrada por Costa no projeto $A$ arte como processo de Recriação em Presídios, publicado pela Secretaria Municipal de Cultura em 1983. Logo na capa da publicação percebe-se um esforço de articulação e organização das ações culturais dentro da Penitenciária Feminina da Capital, pois, para além do patrocínio da Secretaria Municipal de Cultura, está registrado o apoio da "Amaras", uma associação criada para viabilizar o projeto, bem como aparece ainda uma ilustração do Grupo de Teatro da Penitenciária Feminina da Capital para o espetáculo Nós de Valor... Nós de Fato. Além disso, Costa afirma que "através dos personagens, essas pessoas passam a ter um entendimento maior de si, do outro, da comunidade social" (Costa, 1983, p. 4). O teatro aparece, portanto, como um potencializador das relações entre a comunidade prisional e a sociedade em geral.

Já na década de 80 Concilio ilumina o trabalho de Ruth Escobar e Roberto Lage - este último já havia desenvolvido trabalhos em "presídios de Taubaté, Tremembé, Araraquara e Presidente Bernardes" (Concilio, 2008, p. 52). A inserção de Ruth Escobar no campo prisional se dá primeiro pela apresentação de espetáculos em presídios,

[...] em 64, com seu caminhão-palco e o grupo de teatro Martins Pena. Oito anos depois retornaria às prisões para apresentar "Missa Leiga", espetáculo dirigido por Ademar Guerra que chegou, inclusive, a ser exibido em algumas prisões portuguesas, também por iniciativa da atriz. (Gonçalves Filho apud Escobar, 1982, p. 176).

Foi a partir desse contato que passou a se interessar pelo universo prisional. Realizou o primeiro espetáculo e dessa experiência resultou uma nova montagem. Dessa vez, o diretor foi Emílio de Biasi, encenando um texto de Chico de Assis. No entanto houve um conflito na prisão entre agentes penitenciários e detentos que acabou com acusação pública a Ruth Escobar como insufladora da rebelião e a transferência dos detentos para outras unidades do interior, encerrando assim o processo (Concilio, 2008, p. 52-59). 
Em seu livro Dossiê de uma Rebelião (1982), Ruth enfatiza a institucionalização dos corpos dos presos e a dificuldade inicial do trabalho, pois:

Foi a partir do quinto mês que começamos a sentir os resultados positivos de nossa organização interna: as verbalizações aumentaram em quase 90\% (no início do grupo, os presos mal falavam e quando se colocavam aparentavam muita culpa), os corpos foram se tornando mais flexíveis, a relação entre eles e a guarda melhorava a olhos nus, e da própria administração recebíamos constantes elogios pelo "novo" comportamento ameno dos presos. (Escobar, 1982, p. 13-14).

Esse trecho sinaliza duas questões importantes: a contradição posta em uma melhoria do comportamento dos presos aos olhos da administração e a liberação expressiva conquistada pelo fazer teatral. Além disso, o uso de terceira pessoa do plural para se referir a "nossa organização interna" é também uma pista referente aos processos que ocorreram durante essa experiência de teatro na prisão. A autora se coloca como parte do grupo, em pé de igualdade com os demais participantes. A expressão organização também precisa ser sublinhada, pois, para além do trabalho no grupo teatral, as discussões sobre direitos e leis ocorridas naquele espaço auxiliaram na auto-organização dos presos, promovendo um “processo de democratização da penitenciária” (Escobar, 1982, p. 15), pois, ao final do primeiro semestre de trabalho, "o grupo de 70 pessoas do teatro também já tinha se organizado, em grupos de assistência jurídica, musical, teatral e comitê de liderança, tudo escolhido com voto aberto." (Escobar, 1982, p. 15).

Esse processo, embora coordenado por Ruth e por uma equipe de outros profissionais, tem um forte protagonismo dos presos que escreveram as peças curtas que constituíram a encenação Aqui há Ordem e Progresso, com duração de 90 minutos, apresentada aos demais detentos da penitenciária e seguida de debates.

Essa encenação foi um sucesso dentro da unidade prisional e foram realizadas apresentações que incluíram público externo, com presença de autoridades do sistema prisional, surgindo inclusive convites para que se realizasse o mesmo tipo de trabalho em outros estados e também que o projeto fosse ampliado para atender guardas. (Escobar, 1982, p. 16). 
A partir de 1991, com os projetos relacionados ao trabalho de Paul Heritage, é possível vislumbrar o desdobramento de novas experiências de teatro em nossas prisões. Heritage (1999) reflete sobre as relações de troca entre o trabalho no Brasil e na Grã-Bretanha da seguinte maneira:

É difícil livrar-se da influência do local onde se originou a produção e resistir ao discurso-padrão do trabalho no qual o Centro TIPP9 embarcou. Os projetos brasileiros têm dado, dessa forma, a oportunidade de distanciar, reexaminar e dar novo enfoque ao trabalho que o Centro TIPP está fazendo na Grã-Bretanha. (Heritage, 1999, p. 69).

Essa consideração aponta certa preocupação de Heritage com a dimensão colonial que está imbricada na assimetria da relação de uma instituição britânica desenvolvendo um trabalho nas penitenciárias do Brasil e o autor se apressa em demonstrar que sua prática estabelece o caminho inverso, ou seja, os resultados das prisões brasileiras influenciam o que é feito na Inglaterra.

Há uma contradição posta pela assimetria que não é explorada em seus textos e que toma corpo com as seguintes afirmações de Concilio (2008) sobre a missão de Heritage no Brasil, sendo a primeira mais ligada a sua trajetória:

Naquele momento, o principal responsável pela divulgação das propostas do TIPP Centre no Brasil era o professor universitário e diretor teatral Paul Heritage, cuja trajetória profissional esteve ligada, desde muito cedo, a trabalhos com a comunidade encarcerada. (Concilio, 2008, p. 57).

Na segunda afirmação aparece mais a finalidade: “[...] Paul é responsável pela divulgação de programas de teatro e educação em prisões, defendendo propostas que reafirmam o direito à dignidade dos prisioneiros." (Concilio, 2008, p. 57).

Essas assertivas parecem auxiliar na caracterização das influências do TIPP Centre sobre o trabalho nas prisões brasileiras e reforçam o objetivo da "dignidade dos prisioneiros". Faço esse apontamento para destacar a problemática de que a ideia de direito a dignidade, um valor humanista e global dos direitos humanos associado à divulgação dos programas do Centro TIPP, precisa ser examinada com

\footnotetext{
9 Theatre in Prisons and Probation Research and Development Centre - TIPP Centre.
} 
cautela. Os programas desenvolvidos pelo Centro na Inglaterra e em outros países possuem metodologias e práticas alinhadas com políticas e ideologias do local de origem. O próprio autor corrobora ao afirmar que no centro TIPP: "O trabalho tem se desenvolvido de modo a atender ao clima ideológico e financeiro" (Heritage, 1999, p. 69). Portanto, ao divulgar e realizar trabalhos no Brasil é difícil crer que as trocas sejam igualitárias, que apenas os resultados brasileiros influenciem o projeto inglês e não vice-versa.

As peças que resultaram desse trabalho foram construídas com base em metodologias do Teatro Imagem de Augusto Boal e articulando seu Teatro do Oprimido com as bases pedagógicas de Paulo Freire. Além disso, Heritage misturou referências do trabalho teatral desenvolvido nas prisões inglesas, mas que segundo ele "se tornou caracteristicamente brasileiro. Usando um estilo eclético extraído da capoeira, do carnaval e das novelas [...]" (Heritage, 1999, p. 72). No Centro de Internamento e Reeducação da Penitenciária da Papuda a peça foi sobre a escravidão do período colonial e depois se somaram cenas que falavam da escravidão contemporânea. No Núcleo de Custódia, a peça foi construída a partir do poema Oh! Por que Brasil?, escrito por Moisés (um dos homens presos), cuja temática era a desigualdade no Brasil. Heritage ressalta, entre as diferenças do trabalho no Brasil e na Inglaterra, o fato de que lá "a maioria do trabalho que produzimos é controlado pelas autoridades de maneira tal que resta pouco mais de uma lembrança quando partimos" (Heritage, 1999, p. 73), e que no Brasil a pouca estrutura educacional, no caso da Papuda, permitiu uma permanência do teatro. Devido à falta de professores na unidade, a solução adotada para que os presos tivessem seu acesso à educação respeitado foi um sistema de monitoria. Quem aprende ensina aos demais e esse procedimento ocorreu também com o teatro, que teve continuidade no ano de 1994 com a manutenção de um grupo de teatro regular.

Outro projeto desenvolvido por Heritage foi o Projeto Drama-DST/AIDS ${ }^{10}$, uma parceria entre o TIPP-Centre, a Universidade de Manchester e a Unicamp, e tinha

10 O nome do projeto é composto pelas siglas cuja significação é amplamente conhecida: DST- Doenças Sexualmente Transmissíveis e AIDS - Síndrome da Imunodeficiência Adquirida. 
por objetivo trabalhar questões relacionadas à saúde nas prisões. Ao examinar os aspectos pedagógicos do Projeto Drama - DST/AIDS, Concilio detalha dimensões da metodologia vinculadas à ideia de Teatro Aplicado, bem como o encontro com o Centro de Teatro do Oprimido, que atuou simultaneamente em mais de 30 unidades prisionais. (Concilio, 2008, p. 59-65).

Em 1996, Jorge Rodrigo N. Spínola começou a ministrar como voluntário uma oficina teatral na Penitenciária de Guarulhos, em seguida mudou a oficina para a Penitenciária Feminina do Butantã e em 1997 iniciou um projeto de Teatro nas Prisões no Centro de Observações Criminológicas do Complexo Prisional do Carandiru, desenvolvido pela Secretaria da Administração Penitenciária com apoio da Fundação Professor Dr. Manoel Pedro Pimentel (FUNAP)11. O projeto atingiu em sua existência 17 unidades prisionais. O trabalho teve início em 1998, os integrantes cursavam o ensino fundamental e, depois disso, participavam das oficinas de teatro. A primeira oficina contou com 25 pessoas. Um dos resultados foi a encenação de O Auto da Compadecida, de Ariano Suassuna, tendo no elenco os seguintes artistas presos: Valdenilson R. de Souza, Wagner Cintra Lopes, Agnaldo S. da Silva, Walffi Magalhães, Cristian Salazar, Luiz Augusto Cerigola, Isaac M. Rodrigues, Osias Silva dos Santos, Rivadávia Serafim, Alexandre Kamada e Fábio Comette Cardoso. O cenário foi montado também por oito detentos em regime semiaberto do Presídio Franco da Rocha. A peça foi apresentada dentro da prisão para cerca de mil pessoas presas, foi apresentada também na Penitenciária Feminina do Butantã em 1999 e conseguiu extrapolar os muros do cárcere em três dias de apresentação, um no Teatro da Universidade Católica em 24 de junho, e em 13 e 14 de agosto do mesmo ano no Teatro Sérgio Cardoso, ambos na cidade de São Paulo.

Teatro na prisão na contemporaneidade: apontamentos

Natália Ribeiro Fiche, em sua dissertação Teatro na Prisão: trajetórias

${ }^{11}$ A sigla FUNAP é o nome mais conhecido da Fundação Prof. Dr. Manoel Pedro Pimentel criada pelo governo de São Paulo em 1976. 
individuais, perspectivas coletivas, aborda a história do projeto de extensão Teatro na Prisão: uma experiência pedagógica em busca do sujeito cidadão ${ }^{12}$, por meio da realização de entrevistas com sete alunos de graduação que participaram do projeto nos seus primeiros 10 anos. Seu texto se divide em duas partes, na primeira se dedica a refletir sobre a história das prisões no Brasil e o quadro atual do sistema carcerário. Propõe-se também a fazer indagações sobre a prisão na perspectiva do teatro, debruça-se sobre questões referentes ao corpo da pessoa encarcerada e faz um balanço histórico sobre o projeto de extensão. Na segunda parte são examinadas as entrevistas realizadas e propostas reflexões sobre os processos pedagógicos desenvolvidos, na busca por responder quanto aos processos de tomada de consciência dos estudantes envolvidos e às influências na sua formação como professores.

As encenações realizadas de 1997 até 2006 estão registradas e analisadas em muitos de seus aspectos na dissertação de Natália Fiche. Porém, o projeto completou, em 2019, 22 anos de existência e, diante disso, optei aqui apenas por relacionar título, ano e local, sem pormenorizar metodologias e objetivos propostos e ou atingidos, como foi feito nos outros casos levantados, dado o volume de informações que daí decorreriam. Desse modo, apresento a seguir um quadro com as realizações de peças, cenas, jogos e, em alguns casos, anotações sobre processos de trabalho que por motivos diversos não resultaram em apresentações.

Quadro 1 - Encenações

\begin{tabular}{|l|c|c|c|l|}
\hline Ano & $\begin{array}{c}\text { Título da } \\
\text { Encenação }\end{array}$ & Autor & $\begin{array}{c}\text { Unidade } \\
\text { Prisional }\end{array}$ & Breve descrição \\
\hline 1997 & Candelariamente & $\begin{array}{c}\text { Criação } \\
\text { Coletiva }\end{array}$ & $\begin{array}{c}\text { Penitenciária } \\
\text { Lemos Brito }\end{array}$ & $\begin{array}{l}\text { Criada a partir de um poema do integrante Natalino e } \\
\text { de improvisações diversas com o grupo. }\end{array}$ \\
\hline 1998 & O Baile & $\begin{array}{c}\text { Criação } \\
\text { Coletiva }\end{array}$ & $\begin{array}{c}\text { Penitenciária } \\
\text { Lemos Brito }\end{array}$ & $\begin{array}{c}\text { Texto de José Luis } \\
\text { Silvério e Roberto William C. Francisco, internos da } \\
\text { unidade. }\end{array}$ \\
\hline
\end{tabular}

\footnotetext{
${ }^{12}$ O projeto foi fundado em 1997 por Natalia Ribeiro Fiche e Maria de Lourdes Naylor Rocha em consequência de uma oficina realizada com Paul Heritage. Em 2010, quando passei a coordenar o projeto junto com Natália Fiche, ampliamos suas ações constituindo o programa de extensão Cultura na Prisão.
} 


\begin{tabular}{|c|c|c|c|c|}
\hline 1999 & $\begin{array}{l}\text { Rádio era uma } \\
\text { vez }\end{array}$ & $\begin{array}{l}\text { Criação } \\
\text { Coletiva }\end{array}$ & $\begin{array}{l}\text { Penitenciária } \\
\text { Lemos Brito }\end{array}$ & $\begin{array}{l}\text { Um dos integrantes trouxe um texto que deu origem } \\
\text { a dramaturgia. }\end{array}$ \\
\hline 2000 & $\begin{array}{l}\text { O Pagador de } \\
\text { Promessas }\end{array}$ & Dias Gomes & $\begin{array}{l}\text { Penitenciária } \\
\text { Lemos Brito }\end{array}$ & $\begin{array}{l}\text { Esta peça foi apresentada em diversas ocasiões } \\
\text { dentro do auditório da penitenciária até o ano de } 2001 .\end{array}$ \\
\hline 2000 & Bumba Meu Boi & $\begin{array}{l}\text { Criação } \\
\text { Coletiva }\end{array}$ & $\begin{array}{l}\text { Penitenciária } \\
\text { Lemos Brito }\end{array}$ & $\begin{array}{l}\text { A partir dos folguedos brasileiros foi criada para } \\
\text { festejo de dia das crianças na penitenciária. }\end{array}$ \\
\hline 2000 & $\begin{array}{l}\text { Sistema da } \\
\quad \text { Rotina }\end{array}$ & $\begin{array}{l}\text { Criação } \\
\text { Coletiva }\end{array}$ & $\begin{array}{l}\text { Presídio } \\
\text { Nélson } \\
\text { Hungria }\end{array}$ & $\begin{array}{l}\text { A partir de histórias vividas pelas internas do presídio } \\
\text { relatando o dia a dia da prisão. }\end{array}$ \\
\hline 2001 & O Sonho Perdido & $\begin{array}{l}\text { Criação } \\
\text { Coletiva }\end{array}$ & $\begin{array}{l}\text { Presídio } \\
\text { Nélson } \\
\text { Hungria }\end{array}$ & $\begin{array}{l}\text { Criação a partir da história de violência sexual sofrida } \\
\text { por uma das integrantes do grupo. }\end{array}$ \\
\hline 2001 & $\begin{array}{l}\text { O Pagador de } \\
\text { Promessas }\end{array}$ & Dias Gomes & $\begin{array}{l}\text { Penitenciária } \\
\text { Lemos Brito }\end{array}$ & A peça seguiu com apresentações durante esse ano. \\
\hline 2002 & O verdugo & Hilda Hilst & $\begin{array}{l}\text { Penitenciária } \\
\text { Lemos Brito }\end{array}$ & $\begin{array}{l}\text { O processo de encenação desta peça durou um ano } \\
\text { e oito meses. A peça foi apresentada em diversas } \\
\text { ocasiões dentro do auditório da penitenciária e em } \\
\text { outras unidades do Sistema até o ano de } 2004 \text {. }\end{array}$ \\
\hline 2002 & $\begin{array}{l}\text { Precisa-se } \\
\text { Ocupar essa } \\
\quad \text { Vaga? }\end{array}$ & $\begin{array}{l}\text { Criação } \\
\text { Coletiva }\end{array}$ & $\begin{array}{l}\text { Presídio } \\
\text { Nélson } \\
\text { Hungria }\end{array}$ & $\begin{array}{l}\text { Criação do grupo sobre o problema das pessoas que } \\
\text { já cumpriram suas penas e continuam presas. }\end{array}$ \\
\hline 2003 & O verdugo & Hilda Hilst & $\begin{array}{l}\text { Penitenciária } \\
\text { Lemos Brito }\end{array}$ & $\begin{array}{l}\text { O processo de encenação desta peça durou um ano } \\
\text { e oito meses. A peça foi apresentada em diversas } \\
\text { ocasiões dentro do auditório da penitenciária e em } \\
\text { outras unidades do Sistema até o ano de } 2004 \text {. }\end{array}$ \\
\hline 2004 & O verdugo & Hilda Hilst & $\begin{array}{l}\text { Penitenciária } \\
\text { Lemos Brito }\end{array}$ & $\begin{array}{l}\text { O processo de encenação desta peça durou um ano } \\
\text { e oito meses. A peça foi apresentada em diversas } \\
\text { ocasiões dentro do auditório da penitenciária e em } \\
\text { outras unidades do Sistema até o ano de } 2004 \text {. }\end{array}$ \\
\hline 2005 & $\left|\begin{array}{c}\text { O Escorpião e os } \\
\text { dois Crocodilos }\end{array}\right|$ & $\begin{array}{l}\text { Criação } \\
\text { Coletiva }\end{array}$ & $\begin{array}{l}\text { Penitenciária } \\
\text { Lemos Brito } \\
\end{array}$ & Criada a partir de fábula homônima. \\
\hline 2006 & $\left|\begin{array}{c}\text { Os Meninos de } \\
\text { Rua Mutantes e } \\
\text { Miseráveis }\end{array}\right|$ & $\begin{array}{l}\text { Criação } \\
\text { Coletiva }\end{array}$ & $\begin{array}{l}\text { Penitenciária } \\
\text { Lemos Brito }\end{array}$ & $\begin{array}{l}\text { Criada a partir da obra Os Miseráveis, de Victor Hugo, } \\
\text { e de Aquele que diz sim, aquele que diz não, de Bertolt } \\
\text { Brecht. }\end{array}$ \\
\hline 2006 & $\begin{array}{l}\text { Garotas da } \\
\text { Custódia }\end{array}$ & $\begin{array}{l}\text { Criação } \\
\text { Coletiva }\end{array}$ & $\begin{array}{c}\text { Casa de } \\
\text { Custódia } \\
\text { Romeiro Neto }\end{array}$ & Criado a partir de improvisações diversas. \\
\hline 2007 & $\begin{array}{l}\text { Não houve } \\
\text { encenação }\end{array}$ & & DEGASE & Apenas processo de trabalho com os jovens. \\
\hline 2008 & $\begin{array}{c}\text { Aquele que diz } \\
\text { sim, aquele que } \\
\text { diz não }\end{array}$ & Bertolt Brecht & DEGASE & Improvisos com o texto de Brecht por base. \\
\hline 2008 & $\begin{array}{c}\text { Universo } \\
\text { Shakespeareano } \\
\text { (não houve } \\
\text { apresentação } \\
\text { final) }\end{array}$ & \begin{tabular}{|c|} 
William \\
Shakespeare
\end{tabular} & $\begin{array}{l}\text { Penitenciária } \\
\text { Lemos Brito }\end{array}$ & $\begin{array}{l}\text { Cenas de Hamlet, Ricardo III, Othelo, Macbeth, Rei Lear } \\
\text { e A tempestade. }\end{array}$ \\
\hline
\end{tabular}




\begin{tabular}{|c|c|c|c|c|}
\hline 2009 & $\begin{array}{c}\text { Mulheres que } \\
\text { correm com os } \\
\text { lobos (não houve } \\
\text { apresentação } \\
\text { final) }\end{array}$ & $\begin{array}{c}\text { Clarice } \\
\text { Pinkola Estés }\end{array}$ & $\begin{array}{l}\text { Penitenciária } \\
\text { Joaquim } \\
\text { Ferreira }\end{array}$ & $\begin{array}{l}\text { Jogos a partir dos contos Barba Azul e } \\
\text { O Urso da meia lua. }\end{array}$ \\
\hline 2009 & $\left|\begin{array}{c}\text { Dois Perdidos } \\
\text { numa noite suja }\end{array}\right|$ & Plínio Marcos & $\begin{array}{l}\text { Penitenciária } \\
\text { Lemos Brito }\end{array}$ & Improvisação a partir do texto original. \\
\hline 2010 & $\left|\begin{array}{c}\text { Aula espetáculo } \\
\text { de cima pra } \\
\text { baixo }\end{array}\right|$ & $\begin{array}{l}\text { Arthur } \\
\text { Azevedo }\end{array}$ & $\begin{array}{l}\text { Penitenciária } \\
\text { Lemos Brito }\end{array}$ & $\begin{array}{l}\text { Aula encenada a partir do trabalho com o texto De } \\
\text { cima pra baixo. }\end{array}$ \\
\hline 2010 & $\left|\begin{array}{c}\text { Mini espetáculo } \\
\text { Cortejo de } \\
\text { histórias }\end{array}\right|$ & $\begin{array}{l}\text { Criação } \\
\text { Coletiva }\end{array}$ & $\begin{array}{l}\text { Penitenciária } \\
\text { Oscar } \\
\text { Stevenson }\end{array}$ & $\begin{array}{l}\text { A partir de trabalho com músicas e fragmentos de } \\
\text { histórias das integrantes do grupo. }\end{array}$ \\
\hline 2011 & Ovelha Negra & Ítalo Calvino & $\begin{array}{l}\text { Penitenciária } \\
\text { Lemos Brito }\end{array}$ & Criado a partir do conto homônimo de Calvino. \\
\hline 2012 & $\begin{array}{l}\text { Cena de Teatro } \\
\text { Fórum sem } \\
\text { título }\end{array}$ & $\begin{array}{l}\text { Criação } \\
\text { Coletiva }\end{array}$ & $\begin{array}{l}\text { Penitenciária } \\
\text { Talaver Bruce }\end{array}$ & $\begin{array}{l}\text { Cena construída a partir dos problemas das } \\
\text { integrantes em relação a seus filhos. }\end{array}$ \\
\hline 2013 & Romeu e Julieta & $\begin{array}{c}\text { William } \\
\text { Shakespeare }\end{array}$ & $\begin{array}{l}\text { Penitenciária } \\
\text { Talavera } \\
\text { Bruce }\end{array}$ & $\begin{array}{l}\text { Criação a partir do texto original, tendo final alterado } \\
\text { pelas integrantes do grupo. }\end{array}$ \\
\hline 2013 & A Ralé & Máximo Gorki & $\begin{array}{l}\text { Penitenciária } \\
\text { Lemos Brito }\end{array}$ & Adaptação da peça feita pelo grupo. \\
\hline 2014 & $\begin{array}{l}\text { As Bruxas de } \\
\text { Salém }\end{array}$ & Arthur Muller & $\begin{array}{l}\text { Penitenciária } \\
\text { Talavera } \\
\text { Bruce }\end{array}$ & Adaptação da peça feita pelo grupo. \\
\hline 2014 & $\begin{array}{l}\text { Cartola, futebol } \\
\text { clube }\end{array}$ & $\begin{array}{l}\text { Criação } \\
\text { Coletiva }\end{array}$ & $\begin{array}{l}\text { Penitenciária } \\
\text { Industrial } \\
\text { Esmeraldino } \\
\text { Bandeira }\end{array}$ & $\begin{array}{l}\text { Criação coletiva a partir da leitura de Chapetuba } \\
\text { Futebol Clube de Vianninha. }\end{array}$ \\
\hline 2014 & $\left|\begin{array}{c}\text { Cena de Teatro } \\
\text { Fórum intitulada } \\
\text { O Passinho }\end{array}\right|$ & $\begin{array}{l}\text { Criação } \\
\text { Coletiva }\end{array}$ & $\begin{array}{l}\text { Penitenciária } \\
\text { Evaristo de } \\
\text { Moraes }\end{array}$ & $\begin{array}{l}\text { Criação do grupo a partir de uma improvisação sobre } \\
\text { um jovem que ficava dividido entre dançar nos bailes, } \\
\text { a relação com a família, a religião e o tráfico. }\end{array}$ \\
\hline 2014 & A Bandeira & $\begin{array}{l}\text { Criação } \\
\text { Coletiva }\end{array}$ & $\begin{array}{l}\text { Unidade } \\
\text { Materno } \\
\text { Infantil }\end{array}$ & Exercício de Estética do Oprimido. \\
\hline 2015 & $\begin{array}{l}\text { Homens de } \\
\text { Papel }\end{array}$ & Plínio Marcos & $\begin{array}{l}\text { Penitenciária } \\
\text { Evaristo de } \\
\text { Moraes }\end{array}$ & Criação a partir da obra de Plínio Marcos. \\
\hline 2015 & Gota D’Água & $\begin{array}{l}\text { Chico } \\
\text { Buarque e } \\
\text { Paulo Pontes }\end{array}$ & $\begin{array}{l}\text { Penitenciária } \\
\text { Talavera } \\
\text { Bruce }\end{array}$ & Adaptação da peça feita pelas integrantes do grupo. \\
\hline
\end{tabular}




\begin{tabular}{|c|c|c|c|c|}
\hline 2015 & $\begin{array}{l}\text { A Abolição da } \\
\text { Escravatura }\end{array}$ & \begin{tabular}{|l} 
Millôr \\
Fernandes e \\
Flavio Rangel
\end{tabular} & $\begin{array}{l}\text { Penitenciária } \\
\text { Industrial } \\
\text { Esmeraldino } \\
\text { Bandeira }\end{array}$ & Cena adaptada da peça Liberdade... Liberdade. \\
\hline 2015 & $\begin{array}{l}\text { Gran Circo } \\
\text { Esmeral }\end{array}$ & \begin{tabular}{|l} 
Criação \\
Coletiva
\end{tabular} & $\begin{array}{l}\text { Penitenciária } \\
\text { Industrial } \\
\text { Esmeraldino } \\
\text { Bandeira }\end{array}$ & $\begin{array}{l}\text { Criação do grupo para apresentação na festa de fim } \\
\text { de ano para os familiares. }\end{array}$ \\
\hline 2016 & $\begin{array}{l}\text { Contação de } \\
\text { histórias }\end{array}$ & $\begin{array}{l}\text { Criação } \\
\text { Coletiva }\end{array}$ & $\begin{array}{l}\text { Penitenciária } \\
\text { Industrial } \\
\text { Esmeraldino } \\
\text { Bandeira }\end{array}$ & $\begin{array}{l}\text { Trabalho criado a partir de técnica de contação de } \\
\text { histórias. }\end{array}$ \\
\hline 2016 & $\begin{array}{c}\text { Memórias: } \\
\text { pequenas cenas }\end{array}$ & $\begin{array}{l}\text { Criação } \\
\text { Coletiva }\end{array}$ & $\begin{array}{l}\text { Penitenciária } \\
\text { Talavera } \\
\text { Bruce }\end{array}$ & Criado a partir das histórias das integrantes do grupo. \\
\hline 2016 & $\begin{array}{c}\text { Aquele que diz } \\
\text { sim, aquele que } \\
\text { diz não }\end{array}$ & Bertolt Brecht & $\begin{array}{l}\text { Penitenciária } \\
\text { Evaristo de } \\
\text { Moraes }\end{array}$ & Criação a partir da obra homônima de Brecht. \\
\hline 2016 & $\begin{array}{l}\text { Nega do cabelo } \\
\text { duro }\end{array}$ & $\begin{array}{l}\text { Criação } \\
\text { Coletiva }\end{array}$ & $\begin{array}{l}\text { Penitenciária } \\
\text { Talavera } \\
\text { Bruce }\end{array}$ & $\begin{array}{l}\text { Criação a partir de discussões raciais e de } \\
\text { autocuidado. }\end{array}$ \\
\hline 2017 & Mulheres & $\begin{array}{l}\text { Eduardo } \\
\text { Galeano }\end{array}$ & $\begin{array}{l}\text { Penitenciária } \\
\text { Oscar } \\
\text { Stevenson }\end{array}$ & Criação a partir do texto de Galeano. \\
\hline 2017 & Édipo Rei & Sófocles & $\begin{array}{l}\text { Penitenciária } \\
\text { Evaristo de } \\
\text { Moraes }\end{array}$ & Criação a partir do texto de Sófocles. \\
\hline 2018 & $\begin{array}{l}\text { É dia de Feira - } \\
\text { Cena Curta }\end{array}$ & $\begin{array}{l}\text { Criação } \\
\text { Coletiva }\end{array}$ & & $\begin{array}{l}\text { A partir de improvisações cujo local era uma feira em } \\
\text { que todos competiam para vender mais barato. }\end{array}$ \\
\hline 2018 & $\begin{array}{l}\text { Zora - Cena } \\
\quad \text { Curta }\end{array}$ & |́́talo Calvino & $\begin{array}{l}\text { Penitenciária } \\
\text { Evaristo de } \\
\text { Moraes }\end{array}$ & Criação a partir do Livro Cidades Invisíveis. \\
\hline 2019 & \begin{tabular}{|cc}
\multicolumn{2}{|c}{ Objetos } \\
\multicolumn{2}{|c}{ Femininos } \\
(trabalho em \\
fase \\
elaboração)
\end{tabular} & $\begin{array}{l}\text { Criação } \\
\text { Coletiva }\end{array}$ & $\begin{array}{l}\text { Penitenciária } \\
\text { Evaristo de } \\
\text { Moraes - } \\
\text { Grupo } \\
\text { LGBTQI+ }\end{array}$ & $\begin{array}{l}\text { Criação a partir de cartas que relatam a falta de } \\
\text { objetos femininos para a população LGBTQIA+ da } \\
\text { unidade masculina e os objetos criados pelo grupo } \\
\text { para suprir essa carência. }\end{array}$ \\
\hline 2019 & $\begin{array}{l}\text { Oásis } \\
\text { (trabalho em } \\
\text { fase de } \\
\text { elaboração) }\end{array}$ & $\begin{array}{l}\text { Caio } \\
\text { Fernando } \\
\text { Abreu }\end{array}$ & $\begin{array}{l}\text { Penitenciária } \\
\text { Evaristo de } \\
\text { Moraes }\end{array}$ & $\begin{array}{l}\text { Criação a partir do texto homônimo de Caio Fernando } \\
\text { Abreu. }\end{array}$ \\
\hline
\end{tabular}

De 1997 até 2001 prevaleceu a metodologia do Teatro do Oprimido, aos 
moldes do que foi proposto por Paul Heritage. As montagens das peças O Pagador de Promessas e O Verdugo seguiram caminhos diferentes, embora no processo de criação tenham sido adotados procedimentos do Teatro Imagem e jogos de TO, foi adotada também a perspectiva pedagógica de Ryngaert, criando um processo de trabalho mais híbrido. Esse processo, por força da pesquisa e interesse de integrantes da equipe, foi utilizado novamente em 2005 e 2006, embora em 2002 a criação de Precisa-se ocupar essa vaga? tenha retomado as técnicas de Boal exclusivamente. Já em 2006, o espetáculo Garotas da Custódia foi construído com técnicas totalmente diversas, foi desenvolvido com as mulheres um trabalho de música orgânica e de Contato Improvisação. Já de 2007 a 2010 prevaleceu uma ênfase nos processos criativos mais do que nos produtos finais. Essa guinada tem pelo menos duas dimensões, por um lado acompanhavam certos debates do meio acadêmico trazidos pelos estudantes da Unirio integrantes do projeto, por outro encontravam as barreiras postas pelo próprio sistema prisional.

Outro aspecto na diversificação metodológica tem relação com o aumento gradual do número de unidades prisionais atendidas e as diversas realidades vivenciadas. A partir de 2010, retoma-se o foco de realizar apresentações finais com os grupos das variadas oficinas de forma mais aberta, incluindo-se, além de peças teatrais, cenas curtas e outras modalidades de produção final, conforme os processos e desafios enfrentados em cada prisão. As técnicas do Teatro do Oprimido também foram retomadas com mais força, tendo inclusive sido realizadas oficinas ministradas pelo Centro de Teatro do Oprimido para os estudantes da Unirio. Outro dado fundamental para o trabalho que passou a ser desenvolvido desde então é a perspectiva emancipatória, com base em preceitos da educação popular de base freireana. A ideia da pedagogia da autonomia passou a ser aprofundada no que se refere às práticas desenvolvidas com os internos do sistema nas oficinas, mas também em relação aos estudantes da universidade que ministram as oficinas supervisionadas pelas professoras responsáveis pelo projeto.

Em 2017, o projeto Teatro no Presídio Feminino de Florianópolis foi criado por Vicente Concilio. Mas sua história remonta tanto à trajetória de Concilio trabalhando com Spínola em São Paulo como aos processos de entrada nas 
instituições prisionais em Florianópolis.

Sua primeira tentativa de fazer uma oficina de teatro na prisão foi em 2009, no Presídio Feminino de Florianópolis, que durou apenas três meses. Muitas dificuldades surgiram, incluindo a falta de espaço, falta de divulgação da proposta entre as mulheres encarceradas e, o mais importante, a indisponibilidade dos agentes penitenciários para acompanhar o workshop.

No ano seguinte, em 2010, a mesma prisão permitiu que uma estudante universitária, Karine de Oliveira Cupertino, trabalhando sob a supervisão do professor Concilio, realizasse uma oficina. O fato de a universitária ser uma mulher ajudou a diminuir alguns dos problemas que ele havia enfrentado por conta própria, mas embora ela enfrentasse menos problemas, a oficina acabou com apenas uma integrante. (Lucas, Fiche e Concilio, 2019, p. 10-11).

O contato com o Programa de Extensão Cultura na Prisão e com a Professora Ashley Lucas em evento realizado na Unirio são apontados pelos autores como impulsionadores do projeto de Concilio, assim como a organização dos professores da Faculdade de Educação da Universidade do Estado de Santa Catarina que resultou na criação do Programa Novos Horizontes. Esse programa incide em variados aspectos da educação prisional. Os obstáculos enfrentados e as primeiras conquistas do projeto no Presídio Feminino de Florianópolis têm seus primeiros registros e reflexões não apenas no artigo supracitado, mas também por meio da produção de estudantes que atuam no projeto.

Entre 2002 e 2008, na cidade de Porto Alegre, ocorreram oficinas de Teatro na Fundação de Atendimento Socioeducativo do Rio Grande do Sul. Não encontrei muitas informações sobre essa experiência, por isso ela não consta na Linha do Tempo, mas há pelo menos um trabalho de conclusão de curso da Licenciatura em Teatro da Universidade Federal do Estado do Rio Grande do Sul que relata a atuação da estudante nas oficinas. O teatro como protagonista na ressocialização de jovens em conflito com a lei, de Izabel Cristina da Silveira (2011). Esse apontamento reforça o caráter não totalizante da sistematização proposta, pois certamente há mais eventos que poderiam ser somados e que me escaparam. 


\section{A História do Teatro nas prisões como história de resistências}

Concluindo essa visada histórica, outros elementos precisam ser acionados para a compreensão da importância de sistematizar a história dessas práticas.

Os antecedentes históricos, ou seja, a conexão entre arte e encarceramento com os marcos da escravidão e o estabelecimento das primeiras instituições penais, quando trazidos para a linha temporal, evidenciam que o quadro do nosso sistema prisional atual tem forte relação com a forma como nossa sociedade foi constituída.

De 1937 até 1969 há uma forte conexão do teatro nas prisões do Brasil com as lutas políticas e sociais stricto sensu. Nos casos da Vila Maria Zélia, de Fernando de Noronha, Itha Grande (na Bahia) e no Presídio Tiradentes o teatro dos presos políticos acontecia vinculado mais diretamente ao Partido Comunista, aliando a formação militante e o debate cultural a um tipo de formação teatral propriamente dita. O teatro aparece como forma de resistência, engajamento e como prática política.

No caso do Teatro do Sentenciado, essa vinculação também se faz presente, porém dissociada do Partido Comunista, uma vez que a trajetória de Abdias Nascimento, bastante heterodoxa, considerando sua adesão ao integralismo, estava ligada a outras forças políticas vinculadas à luta antirracista com contornos específicos do período. Considerando que o Teatro Tupã - A Voz Nacional, que ocorreu também na ilha de Fernando de Noronha, era ligado aos integralistas, há também um forte indício do uso do teatro como ferramenta de formação política por essas organizações.

O Teatro do Sentenciado se revela também como uma fonte de estudos das mais relevantes, tendo em vista que contou com a participação de um dos mais importantes intelectuais de nosso país. A trajetória do T.S também revela aspectos importantes do debate de classe e raça, pois ao sair da prisão Abdias Nascimento, tendo vivido sua primeira experiência teatral como artista no Carandiru, fundou o Teatro Experimental do Negro. 
De 1969 a 1973, com o sequestro de integrantes do Arena, a prisão de Boal e a prisão de Frei Betto, aquilo que pode ser chamado de uma tradição de atuação cultural pecebista nas prisões passará a conviver com as práticas culturais e educativas de uma nova esquerda que estava emergindo no período. Daí que o teatro que faziam, seja transformando a prisão em lugar de estudo como afirma Boal, seja por meio dos círculos bíblicos com Frei Betto, passou a ter em vista a acepção freireana de "Educação Popular", diferenciando-se dos teatros nas prisões anteriores, uma vez que aqueles, embora de base popular e militante, tinham suportes ideológicos mais pertinentes aos modelos das organizações que os influenciavam.

Mais camadas de uma dimensão política e organizativa aparecem nos casos do teatro nas prisões desenvolvido por Maria Rita Freire Costa e por Ruth Escobar. No primeiro, a mudança de nome do projeto, apontando para mais protagonismo das pessoas presas, reflete uma premissa da educação popular. No segundo, a ênfase na auto-organização, por meio das comissões, evidencia aspectos da tradição pecebista, transformada pela nova esquerda, mas possivelmente atravessada pela lógica populista. No entanto, é necessário ressaltar que a tensão posta por essa mistura de concepções e a auto-organização atrelada a uma liderança hierárquica pode ter gerado também níveis de emancipação daqueles sujeitos.

Diante das especificidades levantadas que dizem tanto do teatro no contexto prisional, cabe problematizar. Seria esse um teatro à margem da história do teatro? As ideias de centro e margem parecem não refletir as questões que envolvem esse teatro feito na prisão, que é instituição das mais centrais do capitalismo. De fato, esse teatro está inserido na história, uma vez que o apagamento sistemático de experiências dessa natureza expressa necessariamente um mecanismo de propagação da história, no caso a dos vencedores, como explica Walter Benjamin (1985).

Ao considerar todas essas experiências para uma história do teatro nas prisões é imprescindível lembrar que são expressões de um setor ainda quase totalmente silenciado da sociedade, a população carcerária. Há sem dúvida 
inúmeros intelectuais orgânicos nas prisões, no sentido gramsciano, e um grande número de intelectuais que estiveram encarcerados e produziram conhecimento nas prisões, mas a dimensão de vozes que ultrapassam os muros da prisão ainda é por demais fragilizada. Não se trata de dizer, com isso, que estou apta a falar por presas e presos, que este trabalho representa em alguma medida essas vozes silenciadas, mas que, como pesquisadora livre, branca e de classe trabalhadora não precarizada, ocupo um lugar privilegiado em relação a esse setor da sociedade. Tal privilégio tem gradações na medida em que se dá no contexto da sociedade de classes e em seu quadro de machismo estrutural. As lutas dos movimentos sociais contra as opressões têm ensinado que é papel de quem ocupa espaços de poder, mesmo que transitórios e permeados por níveis de opressão, se colocar em defesa daqueles que estão submetidos às lógicas opressoras. Nesse sentido, o privilégio deve ser útil aos grupos sociais, não falando por eles, mas enunciando aquilo que thes é vedado falar e se convertendo em plataforma que amplifique suas vozes. Assim, realçar o teatro que foi feito por pessoas encarceradas para pessoas encarceradas foi uma das alternativas encontradas para dar consequência a esse pensamento. Resta ainda ressaltar que para quem atua hoje, fazendo ou pesquisando o teatro em e de nossas prisões, o quê fazemos tem história. Ao conhecê-la, podemos encontrar matrizes, perspectivar nossas práticas e projetar as estratégias para enfrentar os desafios do teatro no contexto carcerário, quiçá contribuindo para um teatro sem prisões.

\section{Referências}

BALFOUR, Michael. Theatre in prison: theory and practice. Bristol: Intelect Books, 2004.

BENJAMIN, Walter. As teses sobre o conceito de História. In: Obras Escolhidas. São Paulo: Brasiliense, v. 1, p. 222-232, 1985.

BOAL, Augusto. Hamlet e o filho do padeiro: memórias imaginadas. São Paulo: Cosac Naify, 2014. 
BUDASZ, Rogério. Teatro e música na América Portuguesa - ópera e teatro musical no Brasil (1700-1822): convenções, repertório, raça, gênero e poder. Curitiba: Deartes UFPR, 2008.

CONCILIO, Vicente. Teatro e Prisão: Dilemas da Liberdade Artística. São Paulo: Hucitec, 2008.

CORRÊA, Ademir. Teatro em Cadeia. Revista Ocas, São Paulo, ano 1, n. 10, p. 22 a 25, maio de 2003.

COSTA, Maria Rita Freire. A Arte como Processo de Recriação em Presídios. Catálogo do projeto. São Paulo, 1983.

ESCOBAR, Ruth. Dossiê de uma rebelião. São Paulo: Global, 1982.

FARIA, João Roberto (dir.). História do Teatro Brasileiro. Vol. I - Das origens ao teatro profissional da primeira metade do século XX. São Paulo: Perspectiva, 2012.

FICHE, Natália Ribeiro. Teatro na Prisão: trajetórias individuais e perspectivas coletivas. 2009. Dissertação (Mestrado em Artes Cênicas) UNIRIO. Rio de Janeiro. 2009.

HERITAGE, Paul. Theatre, Prisons and Citizenship: A South American Way. Practices and Perspectives in Prison Theatre. In: THOMPSON, J. Prison Theatre: Perspectives and Practices. Londres: Jessica Kingsley Publishers, 1999.

KOTSCHO, Ricardo. Paulo Freire, Frei Betto: Essa escola chamada vida. São Paulo: Editora Ática, 1988.

LUCAS, Ashley; CONCILIO, Vicente. Uma conversa sobre arte e teatro nas prisões com Ashley Lucas. Urdimento. Florianópolis, v. 2, n. 29, p. 145-156, 2017.

LUCAS, Ashley; FICHE, Natália; CONCILIO, Vicente. We Move Forward Together: A Prison Theatre Exchange Program Among Three Universities in the United States and Brazil. Prison Journal, v. 99, setembro de 2019. Disponível em: https://doi.org/10.1177\%2F0032885519861061. Acesso em: 3 dez. 2019.

MAGALHÃES, Mário. Marighella, o Guerrilheiro que incendiou o mundo. São Paulo: Companhia das Letras, 2012.

NASCIMENTO, Abdias. Do Teatro Brasileiro: O Teatro do Sentenciado. Revista Vamos Ler! Rio de Janeiro, 4 de julho de 1946.

NASCIMENTO, Abdias. Do Teatro Brasileiro: O Teatro do Sentenciado. Revista Vamos Ler! Rio de Janeiro, 11 de julho de 1946.

PERICÁS, Luiz Bernardo. Caio Prado Júnior. uma biografia política. São Paulo: 
Boitempo, 2016.

RUSCHE, Robson Jesus. Teatro, gesto e atitude: investigando a prevenção das DST's e AIDS por meio de técnicas dramáticas com um grupo de presidiários. In: II CONGRESSO INTERNACIONAL DE PEDAGOGIA SOCIAL, 2, 2008, São Paulo. Proceedings online... Faculdade de Educação da Universidade de São Paulo, Disponível em: http://www.proceedings.scielo.br/scielo.phpscript=sci arttext\&pid =MSC0000000092 08000100014\&lng=en\&nrm=abn. Acesso em: 29 jul. 2019.

Recebido em: 12/10/2020

Aprovado em: 06/11/2020 